\title{
Gender Disparities in Posttraumatic Stress Disorder After Mass Trauma
}

\author{
Jennifer Stuber, PhD',2; Heidi Resnick, PhD ${ }^{3}$; and \\ Sandro Galea, MD, MPH, DrPH ${ }^{4,5}$
}

${ }^{1}$ The Division of Health and Science Policy, The New York Academy of Medicine, New York, New York; ${ }^{2}$ Columbia University, New York, New York; ${ }^{3}$ National Crime Victims Research and Treatment Center, Department of Psychiatry and Behavioral Sciences, Medical University of South Carolina, Charleston, South Carolina; ${ }^{4}$ Center for Urban Epidemiologic Studies, The New York Academy of Medicine, New York, New York; and ${ }^{5}$ Department of Epidemiology, University of Michigan School of Public Health, Ann Arbor, Michigan

\begin{abstract}
Background: Although several studies have shown that rates of posttraumatic stress disorder (PTSD) are higher in women than in men, less is known about whether women are more vulnerable to PTSD after a major community-wide traumatic event.

Objective: The aim of this study was to examine gender disparities in the prevalence of probable lifetime PTSD and probable PTSD after a mass traumatic event.

Methods: A representative sample of men and women living in the New York City metropolitan area was selected using random-digit dialing, and subjects were interviewed by telephone 6 to 9 months after the September 11, 2001 (9/11) terrorist attacks. We assessed probable lifetime PTSD and probable PTSD related to the 9/11 attacks using a brief screening instrument and potential correlates.

Results: A total of 2752 individuals (1479 women, 1273 men) were interviewed. The lifetime prevalence of probable PTSD was significantly higher for women than for men $(17.2 \% \mathrm{vs} 12.1 \% ; P=$ 0.005). Experiences of sexual assault $(P<0.001)$, preexisting mental health problems $(P=0.04)$, race/ethnicity $(P=0.01)$, marital status $(P<0.001)$, and having had probable peri-event panic in the first few hours after the $9 / 11$ attacks $(P<0.001)$ were all significantly related to women's greater susceptibility to probable lifetime PTSD. However, the prevalence of probable PTSD related to 9/11 was not significantly different between women and men (6.5\% vs 5.4\%), although women were significantly more likely to report re-experiencing $(P<0.001)$ and hyperarousal $(P<0.001)$ symptoms than were men. Women were more likely than men to experience probable peri-event panic during the $9 / 11$ attacks $(P<0.001)$; this explained, in part, the greater subsequent likelihood of re-experiencing and hyperarousal symptoms among women compared with men.
\end{abstract}

Conclusions: More factors explain the risk of PTSD among women and men after interpersonal trauma than after a disaster. Using peri-event panic symptomatology after a traumatic event to determine the risk of posttraumatic symptoms may suggest avenues for intervention that can decrease the burden of PTSD in women. (Gend Med. 2006;3:54-67) Copyright ( 2006 Excerpta Medica, Inc.

Key words: posttraumatic stress disorder, gender, World Trade Center, panic.

Accepted for publication October 18, 2005.

Printed in the USA. Reproduction in whole or part is not permitted.

$1550-8579 / 06 / \$ 19.00$ 


\section{INTRODUCTION}

Approximately 1 in 12 adults experiences posttraumatic stress disorder (PTSD) at some point during their lifetime. ${ }^{1}$ Studies consistently show that women are at higher risk of PTSD during their lives than are men. ${ }^{1-3}$ Studies also show that more often than not, women appear to be at greater risk for developing PTSD after mass trauma than are men. ${ }^{4,5}$ In a study completed 5 to 8 weeks after the September 11, 2001 (9/11) terrorist attacks, women were more than twice as likely as men were to report symptoms consistent with probable PTSD related to the 9/11 attacks. ${ }^{6}$ In the current study, which is a followup to the aforementioned study, we examined the prevalence of PTSD in women compared with men 6 to 9 months after September 11 .

Much of the research on women's greater vulnerability to PTSD has focused on lifetime assessments. Several hypotheses have been offered in the literature to explain this gender disparity, but rarely is more than one hypothesis explored simultaneously. Why women are at higher lifetime risk for PTSD than are men may be explained by the qualitative gender-related differences in the way traumatic events, particularly assaultive violence, are experienced. ${ }^{7}$ In some studies, women appear to be at greater risk than men for PTSD when exposed to traumatic events involving assaultive violence. ${ }^{8}$ With respect to other categories of traumatic events, gender differences are smaller. Although women's greater vulnerability to PTSD related to assaultive violence is attributable in part to the higher prevalence of rape, gender differences persist when rape is taken into account and despite the fact that, when all forms of assaultive violence are considered (including combat and physical assault), men are more exposed to violence. ${ }^{1}$

It has also been suggested that preexisting mental health problems may lead to gender differences in the prevalence of PTSD. ${ }^{9}$ For reasons that are not well understood, comorbid psychiatric disorders have been shown to contribute to susceptibility to PTSD after a traumatic event. ${ }^{10}$ Although men and women do not differ in the probability of being diagnosed with some psychological condition, there are genderrelated differences in the pattern of specific disorders observed. ${ }^{11}$ Women are more likely to be depressed or to have generalized anxiety disorder during their lifetime, whereas men are more likely to experience substance abuse, conduct disorders, and antisocial behavior. ${ }^{12}$ The specific disorders women are more vulnerable to may be more highly associated with PTSD onset. ${ }^{13}$

Peri-event panic, characterized by sudden and unexpected discrete periods of intense fear or discomfort immediately after a traumatic event, has begun to receive attention as an important risk factor for PTSD. ${ }^{14}$ Research suggests that peri-event panic may increase the risk of developing PTSD through biological and cognitive pathways. ${ }^{15}$ Pulcino et al, ${ }^{6}$ in their study of gender differences in PTSD 5 to 8 weeks after the 9/11 attacks, reported that women experienced peri-event panic symptoms more frequently than did men in the first few hours after the attacks.

Gender differences in the social support available after trauma may also partially explain gender differences in the risk of PTSD. In one metaanalysis, lack of social support was shown to be one of the most important risk factors for PTSD. ${ }^{16}$ The degree of threat imposed by the appraisal of the stressful situation can be mitigated by the anticipated availability of help, because the intrapsychic resources provided by others may enable an individual to cope on his/her own. ${ }^{17}$ Thus, perceived support may play a role by intervening between a stressor and a stress reaction, thereby lessening or preventing a stress appraisal response. ${ }^{18}$

Marriage is another form of social support. In a recent study after the 9/11 attacks, gender differences in the rates of PTSD were largely accounted for by differences in marital status. ${ }^{19}$ On the other hand, for women, being married may also be a risk factor for psychological distress after trauma. Solomon ${ }^{20}$ found that women who perceived themselves as having excellent spousal support were more vulnerable to adverse psychological effects after disasters. She interpreted these findings as indicating that social ties and obligations can be a source of 
stress for married women. It has also been argued that, compared with married men, married women may suffer more psychological distress after trauma because their social roles expose them to higher levels of social conflict. ${ }^{21}$

Recent stressors have been shown to be strong predictors of disaster victims' symptom levels. ${ }^{22}$ However, recent stressors have not been explored as a potential explanation for gender differences in PTSD. This may be a significant area of inquiry, because women's social roles have changed dramatically in the past several decades. Their participation in the paid labor force has been increasing while they have maintained significant responsibilities at home. Further, in the past few decades the number of households headed by women has increased. ${ }^{23}$ Therefore, it may be important to examine not only whether women report experiencing a greater number of recent stressors, but also whether specific types of recent stressors (eg, stress at work, as parents, or in the family) differentially affect how men and women adapt after trauma.

In this article, we describe the prevalence of probable lifetime PTSD and probable PTSD 6 to 9 months after the 9/11 attacks. By assessing both probable lifetime PTSD and probable PTSD after a mass traumatic event, we were able to compare gender disparities in PTSD after interpersonal trauma during a person's lifetime and after exposure to a mass traumatic event. We were also interested in understanding factors that explain gender differences in the likelihood of PTSD. However, unlike many previous studies, we explored several of these factors simultaneously, including those (eg, recent stressors) that had not been previously examined. Specifically, we assessed the following factors: (1) the number of previous life stressors; (2) the type of previous life stressors (sexual assault, nonsexual assault, nonassaultive trauma); (3) preexisting mental health problems; (4) social support (perceived support, group participation, marital status); (5) the number of recent life stressors; (6) the type of recent life stressors (work, family, parenting); and (7) perievent panic. We did not assess biological or genetic explanations for gender differences in
PTSD. Simultaneously examining disparities in probable lifetime PTSD and probable PTSD related to a mass trauma gave us greater leverage to understand how these predictors affect gender disparities in different contexts.

\section{SUBJECTS AND METHODS Subjects}

Data were obtained from a random-digit dial household survey conducted between March 25 and June 25, 2002. The sampling frame for the survey included adults in the New York City metropolitan area. All interviews were conducted in English, Spanish, Mandarin, or Cantonese by trained interviewers using translated and back-translated questionnaires and a computerassisted telephone interview system. Sampling weights were applied to our data to correct potential selection bias related to the number of household telephones, persons in the household, and oversampling.

\section{Data Collection}

We used the National Women's Study (NWS) PTSD module to measure PTSD symptoms. ${ }^{24}$ This measure was selected because it assesses content-specific PTSD symptoms (eg, content of dreams or nightmares) and it has been used in other large-scale, mental-health telephone surveys, thereby allowing for comparisons between this study and PTSD symptomatology after other disasters. The NWS PTSD scale was externally validated in a field trial against the PTSD module of the Structured Clinical Interview for the Diagnostic and Statistical Manual of Mental Disorders, Third Edition, Revised (SCID) administered by mental health professionals. ${ }^{24}$ In the field trial, the instrument sensitivity was 99\% and the specificity was $79 \%$ compared with the SCID diagnosis. Because we used a brief screening instrument administered by a nonclinician asking questions over the telephone, all assessments of PTSD made in this study were considered probable.

This module assessed the presence of criteria B (re-experiencing), C (avoidance/numbing), and $\mathrm{D}$ (hyperarousal) symptoms and determined content for content-specific PTSD symp- 
toms. Lifetime PTSD was based on the presence of necessary criteria $\mathrm{B}, \mathrm{C}$, and D symptoms at any time in the respondent's life (including since the 9/11 attacks). PTSD related to the 9/11 attacks was based on the presence of necessary criteria B, C, and D symptoms since September 11. Respondents were required to report at least 1 re-experiencing symptom, 3 avoidance/ numbing symptoms, and 2 arousal symptoms specific to the attacks since September 11. All B symptoms and a subset of $C$ and $D$ symptoms could be linked directly to the $9 / 11$ attacks by time frame and by content. For both lifetime PTSD and PTSD related to the 9/11 attacks, we used a dichotomous measure of probable PTSD indicating its presence or absence rather than a scalar measure of PTSD symptoms because we were interested in studying respondents with sufficient symptoms to meet the criteria for PTSD.

Respondents were asked about demographic characteristics, including their sex, age, race/ ethnicity (white, black, Hispanic, Asian, other), yearly household income, and education. Lifetime exposure to traumatic events was assessed by modifying an existing measure that asked respondents if they had ever experienced any of 8 possible stressful life events. ${ }^{25}$ Cronbach's $\alpha$ for this scale in our data was 0.75 . A variable was created that was the sum of the number of lifetime traumatic events experienced, coded as $0,1,2$ or 3 , or $\geq 4$ events. We also grouped these variables by the type of trauma experienced. Sexual assault was assessed using the item, "Someone used physical force or threat of force to make you have unwanted sexual contact." Nonsexual assault was assessed with 2 items, "Being attacked with a gun, knife, or some other weapon" and "Being attacked without a weapon but with the intent to kill or seriously injure." If respondents answered "yes" to either item, they were coded as experiencing nonsexual assault. Respondents saying "yes" to any of the remaining items (seeing someone seriously injured or violently killed, being in a natural disaster or a serious accident) were coded as having experienced nonassaultive trauma. Preexisting mental health problems were assessed by asking respondents if within the 12 months preceding the 9/11 attacks they had experienced a mental or emotional problem.

Social support within the 6 months before the 9/11 attacks was measured using 5 self-reported items taken from the Medical Outcomes Study Social Support Survey. ${ }^{26}$ The frequency of group participation in the 6 months preceding the 9/11 attacks was assessed using questions asking how often the individual participated in groups (eg, church, veterans' groups). Marital status was coded using 3 levels: married, divorced/ widowed/separated, and never married.

We asked about 7 recent stressors in the 12 months preceding the 9/11 attacks. We grouped responses into 2 categories: family stress (having a spouse or mate die, getting divorced or separated, having a close family member other than a spouse die, getting married, having a problem with a spouse, or having a problem with a child) and work stress (problems at work). In addition, we ascertained whether the respondent was the parent or primary caretaker of a child aged $<18$ years living in the household and if the parent was a single parent.

We created a composite variable from each respondent's disaster event experiences to identify people who were directly affected by the $9 / 11$ attacks. This variable included having been in the World Trade Center complex during the attacks, having been injured during the attacks, losing possessions or property because of the attacks, having a friend or relative killed during the attacks, losing a job due to the attacks, or being involved in the rescue efforts. Before creating this composite variable, we determined that there were no significant differences between men and women in any of these exposures.

Peri-event panic was measured using a modified version of the Diagnostic Interview Schedule. ${ }^{27}$ The modifications involved the use of phrases to detect symptoms experienced during or shortly after the 9/11 terrorist attacks. We asked about peri-event panic symptomatology in the first few hours after the events of September 11. If the participant reported at least 4 of the symptoms listed for panic attack 
in the Diagnostic and Statistical Manual of Mental Disorders, Fourth Edition (eg, shortness of breath, sweating, chest pain), that person was considered to have a probable diagnosis of peri-event panic disorder. ${ }^{28}$

\section{Statistical Analysis}

We reported overall and gender-specific prevalences of probable lifetime PTSD, of probable PTSD related to 9/11, and of each criterion used in making the probable diagnosis of PTSD related to $9 / 11$. We stratified the data by gender on each of the explanatory variables to assess differences between men and women using 2 -tailed $\chi^{2}$ tests. Because $18 \%$ of the sample had missing data on income, we created a dummy variable to retain these observations. Because women were more likely than men to have probable lifetime PTSD and to meet B and D criteria related to the $9 / 11$ attacks, the associations between covariates and these outcomes were assessed in unstratified analyses, again using 2-tailed $\chi^{2}$ tests.

Separate multivariable models for these 3 outcomes were constructed using the following modeling strategy. Covariates that differed by gender and those also associated with the outcomes were considered for inclusion in multivariable logistic regression models. The final multivariable models were built using manual stepwise model building in which 1 variable at a time was added to determine the sequential effect of adding subsequent variables in relation to each outcome. Variables that accounted for some part of the risk of probable lifetime PTSD or criterion B or criterion D (measured by $>10 \%$ change in the gender regression parameter) were reported. We reported percentage changes in regression parameters for gender with the addition of each subsequent variable. This modeling strategy was used because we were interested in assessing plausible explanations for differences in the prevalence of probable PTSD in men and women in a general population sample. Alternatively, we could have used a modeling strategy in which we stratified by gender or used interaction terms, which would have allowed us to explore whether there were different deter- minants of probable PTSD in men versus women. We used the first modeling strategy mentioned because we were interested in the first of these 2 research questions.

To analyze complex survey weights, we used SUDAAN statistical software (Information Technology Services at the University of Texas at Austin), which utilizes Taylor series linearization. In all analyses, we presented unweighted n's, representing the numbers of persons actually surveyed. Percentages, however, reflected weighted proportions and are computationally congruent with the analyses presented here.

This study was approved by the institutional review board of the New York Academy of Medicine (New York, New York).

\section{RESULTS}

Sample

The overall cooperation rate among those eligible was $56 \%$ (based on the sum of the number of completed interviews, quota-outs, screen-outs, refusals, and premature terminations). ${ }^{29}$ The demographic characteristics of our sample were comparable to the US census. More details about the sample are provided elsewhere. ${ }^{30,31}$

\section{Conditional Risk of Posttraumatic Stress Disorder in Men and Women}

A total of 2752 individuals (1479 women, 1273 men) were interviewed (Table I). Of these, $17.2 \%$ of women and $12.1 \%$ of men reported having a pattern of symptoms consistent with a diagnosis of probable PTSD in their lifetime $(P=$ 0.005). However, rates of probable PTSD related to the $9 / 11$ attacks did not vary significantly by gender ( $6.5 \%$ of women vs $5.4 \%$ of men). This nonsignificant difference was explained by the fact that women were not more likely than men to meet criterion $\mathrm{C}$ for PTSD, although they were more likely to report criterion $\mathrm{B}$ and $\mathrm{D}$ symptoms than were men (B: $24.2 \%$ vs $17.4 \%$; D: $25.4 \%$ vs $16.8 \%$; both, $P<0.001$ ).

\section{Gender Differences in Explanatory Variables}

The women were more likely than the men to be black $(P=0.01)$, to have less education $(P=$ 
Table I. Prevalence of posttraumatic psychopathology related to the September $11(9 / 11)$ attacks in male and female interview respondents.

\begin{tabular}{|c|c|c|c|c|c|c|c|}
\hline & \multicolumn{2}{|c|}{$\begin{array}{c}\text { Total } \\
(\mathrm{N}=2752)\end{array}$} & \multicolumn{2}{|c|}{$\begin{array}{c}\text { Women } \\
(n=1479)\end{array}$} & \multicolumn{2}{|c|}{$\begin{array}{c}\text { Men } \\
(\mathrm{n}=1273)\end{array}$} & \multirow[b]{2}{*}{$P^{\dagger}$} \\
\hline & $\mathrm{n}$ & $\% *$ & $\mathrm{n}$ & $\%$ & $\mathrm{n}$ & $\%$ & \\
\hline \multicolumn{8}{|l|}{ Lifetime PTSD (including PTSD related } \\
\hline PTSD related to the $9 / 11$ attacks & 217 & 5.4 & 126 & 6.5 & 91 & 5.4 & 0.39 \\
\hline \multicolumn{8}{|l|}{ PTSD criterion ${ }^{26}$} \\
\hline Re-experiencing (criterion B) & 682 & 21.1 & 424 & 24.2 & 258 & 17.4 & $<0.001$ \\
\hline Avoidance/numbing (criterion C) & 350 & 10.4 & 210 & 11.0 & 140 & 9.6 & 0.40 \\
\hline Hyperarousal (criterion D) & 694 & 21.4 & 436 & 25.4 & 258 & 16.8 & $<0.001$ \\
\hline
\end{tabular}

PTSD = posttraumatic stress disorder.

*Unweighted $n^{\prime}$ s represent the actual numbers of persons surveyed. Percentages reflect weighted proportions.

$\dagger$ Two-tailed $\chi^{2}$ test of significance.

0.002), and to have less income $(P<0.001)$

(Table II). Women were more likely than men to report sexual assault, but women were less likely to report nonsexual assault (both, $P<$ 0.001). There was not a significant difference between men and women in terms of nonassaultive lifetime traumatic events experienced (eg, living through a natural disaster). Overall, men reported experiencing a greater number of lifetime traumatic events $(P<$ 0.001). Women were more likely than men to report having preexisting mental health problems 12 months before the $9 / 11$ attacks $(P<$ 0.04). They were also more likely than men to report being divorced, widowed, or separated, whereas men were more likely than women to report that they had never married $(P<0.001)$. There were no gender differences in the other forms of social support measured. The women surveyed were more likely than men to report being parents and being single parents (both, $P<0.001)$, but women and men reported similar levels of family and work stress. Although the degree of direct exposure to the $9 / 11$ attacks was comparable in men and women, women were more likely to report having had perievent panic within the first few hours of the 9/11 attacks $(P<0.001)$.

\section{Lifetime Posttraumatic Stress Disorder Symptom Groups}

Most of the explanatory variables were significantly associated with probable lifetime PTSD in unstratified analyses: gender $(P=0.005)$, income $(P<0.001)$, age $(P=0.02)$, race/ethnicity $(P=0.008)$, nonassaultive trauma $(P=0.02)$, nonsexual assault $(P<0.001)$, sexual assault $(P<0.001)$, preexisting mental health problems $(P<0.001)$, marital status $(P<0.001)$, perceived social support $(P<0.001)$, participation in group activities $(P=0.05)$, single-parent status $(P=0.009)$, family stress $(P<0.001)$, work stress $(P<0.001)$, being directly affected by the $9 / 11$ attacks $(P<0.001)$, and peri-event panic $(P<$ 0.001). As shown in Table III, the following factors contributed to women's increased risk of probable lifetime PTSD in the multivariable analyses: race/ethnicity, sexual assault, preexisting mental health problems, marital status, and peri-event panic after the 9/11 attacks. However, men's experiences of nonsexual assault increased their risk of PTSD relative to women. Women's greater exposure to sexual assault explained $51 \%$ of their probable lifetime risk of PTSD relative to men, whereas men's experiences of nonsexual assault explained $50 \%$ of their lifetime risk of PTSD relative to women. 
Table II. Demographic and other characteristics of male and female respondents interviewed after the September $11(9 / 11)$ attacks.

\begin{tabular}{|c|c|c|c|c|c|c|c|}
\hline \multirow[b]{2}{*}{ Demographic Characteristics } & \multicolumn{2}{|c|}{$\begin{array}{c}\text { Total } \\
(\mathrm{N}=2752)\end{array}$} & \multicolumn{2}{|c|}{$\begin{array}{c}\text { Women } \\
(\mathrm{n}=1479)\end{array}$} & \multicolumn{2}{|c|}{$\begin{array}{c}\text { Men } \\
(n=1273)\end{array}$} & \multirow[b]{2}{*}{$P^{\dagger}$} \\
\hline & $\mathrm{n}$ & $\%$ * & $\mathrm{n}$ & $\%$ & $\mathrm{n}$ & $\%$ & \\
\hline $\begin{array}{l}\text { Age, } y \\
\quad<25 \\
\quad 25-34 \\
35-44 \\
45-54 \\
55-64 \\
\geq 65\end{array}$ & $\begin{array}{l}261 \\
667 \\
629 \\
521 \\
333 \\
341\end{array}$ & $\begin{array}{l}13.6 \\
23.9 \\
21.2 \\
18.8 \\
12.1 \\
10.4\end{array}$ & $\begin{array}{l}128 \\
335 \\
324 \\
289 \\
197 \\
206\end{array}$ & $\begin{array}{l}11.4 \\
23.5 \\
20.6 \\
19.7 \\
13.3 \\
11.6\end{array}$ & $\begin{array}{l}133 \\
332 \\
305 \\
232 \\
136 \\
135\end{array}$ & $\begin{array}{r}16.2 \\
24.4 \\
21.9 \\
17.7 \\
10.7 \\
9.1\end{array}$ & 0.06 \\
\hline $\begin{array}{l}\text { Race } \\
\text { White } \\
\text { Hispanic } \\
\text { Black } \\
\text { Asian } \\
\text { Other }\end{array}$ & $\begin{array}{r}1592 \\
465 \\
391 \\
166 \\
91\end{array}$ & $\begin{array}{r}53.2 \\
20.6 \\
16.7 \\
5.4 \\
4.2\end{array}$ & $\begin{array}{r}830 \\
269 \\
233 \\
79 \\
39\end{array}$ & $\begin{array}{r}52.9 \\
21.0 \\
18.8 \\
3.8 \\
3.5\end{array}$ & $\begin{array}{r}762 \\
196 \\
158 \\
87 \\
52\end{array}$ & $\begin{array}{r}53.5 \\
20.2 \\
14.2 \\
7.2 \\
4.9\end{array}$ & 0.01 \\
\hline $\begin{array}{l}\text { Education } \\
\text { Less than high school graduation } \\
\text { High school graduate } \\
\text { College graduate }\end{array}$ & $\begin{array}{r}274 \\
1117 \\
1344\end{array}$ & $\begin{array}{l}10.9 \\
47.6 \\
41.5\end{array}$ & $\begin{array}{l}171 \\
637 \\
664\end{array}$ & $\begin{array}{l}12.2 \\
50.4 \\
37.4\end{array}$ & $\begin{array}{l}103 \\
480 \\
680\end{array}$ & $\begin{array}{r}9.2 \\
44.3 \\
46.3\end{array}$ & 0.002 \\
\hline $\begin{array}{l}\text { Income } \\
\quad<\$ 20,000 \\
\$ 20,000-39,999 \\
\$ 40,000-74,999 \\
\geq \$ 75,000 \\
\text { Data missing }\end{array}$ & $\begin{array}{l}400 \\
512 \\
587 \\
769 \\
484\end{array}$ & $\begin{array}{l}13.8 \\
20.5 \\
20.6 \\
27.2 \\
18.0\end{array}$ & $\begin{array}{l}249 \\
300 \\
326 \\
328 \\
276\end{array}$ & $\begin{array}{l}15.3 \\
20.5 \\
22.3 \\
22.6 \\
19.4\end{array}$ & $\begin{array}{l}151 \\
212 \\
261 \\
441 \\
208\end{array}$ & $\begin{array}{l}11.9 \\
20.5 \\
18.5 \\
32.7 \\
16.4\end{array}$ & $<0.001$ \\
\hline $\begin{array}{l}\text { Previous trauma } \\
\text { Sexual assault } \\
\text { Nonsexual assault } \\
\text { Nonassaultive trauma }\end{array}$ & $\begin{array}{r}196 \\
638 \\
1115\end{array}$ & $\begin{array}{r}6.6 \\
22.2 \\
41.8\end{array}$ & $\begin{array}{l}167 \\
202 \\
610\end{array}$ & $\begin{array}{l}10.0 \\
13.8 \\
42.4\end{array}$ & $\begin{array}{r}28 \\
436 \\
505\end{array}$ & $\begin{array}{r}2.3 \\
32.1 \\
41.1\end{array}$ & $\begin{array}{c}<0.001 \\
<0.001 \\
0.62\end{array}$ \\
\hline $\begin{array}{l}\text { Total no. of lifetime } \\
\text { traumatic experiences } \\
0 \\
1 \\
2-3 \\
\geq 4\end{array}$ & $\begin{array}{l}779 \\
747 \\
744 \\
482\end{array}$ & $\begin{array}{l}28.7 \\
28.8 \\
26.9 \\
15.6\end{array}$ & $\begin{array}{l}487 \\
435 \\
372 \\
185\end{array}$ & $\begin{array}{l}33.0 \\
30.9 \\
25.2 \\
10.9\end{array}$ & $\begin{array}{l}292 \\
312 \\
372 \\
297\end{array}$ & $\begin{array}{l}23.6 \\
26.4 \\
28.9 \\
21.2\end{array}$ & $<0.001$ \\
\hline Preexisting mental health problems & 264 & 7.9 & 160 & 9.2 & 104 & 6.5 & $<0.04$ \\
\hline $\begin{array}{l}\text { Social support available before } \\
\text { the } 9 / 11 \text { attacks } \\
\text { Marital status } \\
\text { Married } \\
\text { Never married } \\
\text { Divorced, widowed, separated }\end{array}$ & $\begin{array}{r}1182 \\
1020 \\
538\end{array}$ & $\begin{array}{l}50.8 \\
34.0 \\
15.1\end{array}$ & $\begin{array}{l}620 \\
475 \\
374\end{array}$ & $\begin{array}{l}50.7 \\
30.0 \\
20.2\end{array}$ & $\begin{array}{l}562 \\
545 \\
164\end{array}$ & $\begin{array}{r}52.0 \\
38.9 \\
9.2\end{array}$ & $<0.001$ \\
\hline $\begin{array}{l}\text { Perceived social support } \\
\text { Low } \\
\text { Medium } \\
\text { High }\end{array}$ & $\begin{array}{r}846 \\
799 \\
1057\end{array}$ & $\begin{array}{l}29.8 \\
31.1 \\
39.1\end{array}$ & $\begin{array}{l}456 \\
438 \\
562\end{array}$ & $\begin{array}{l}29.8 \\
31.9 \\
38.3\end{array}$ & $\begin{array}{l}390 \\
361 \\
495\end{array}$ & $\begin{array}{l}29.9 \\
30.1 \\
40.1\end{array}$ & 0.71 \\
\hline
\end{tabular}


Table II. (Continued)

\begin{tabular}{|c|c|c|c|c|c|c|c|}
\hline \multirow[b]{2}{*}{ Demographic Characteristics } & \multicolumn{2}{|c|}{$\begin{array}{c}\text { Total } \\
(\mathrm{N}=2752)\end{array}$} & \multicolumn{2}{|c|}{$\begin{array}{c}\text { Women } \\
(\mathrm{n}=1479)\end{array}$} & \multicolumn{2}{|c|}{$\begin{array}{c}\text { Men } \\
(\mathrm{n}=1273)\end{array}$} & \multirow[b]{2}{*}{$P^{\dagger}$} \\
\hline & $\mathrm{n}$ & $\% *$ & $\mathrm{n}$ & $\%$ & $\mathrm{n}$ & $\%$ & \\
\hline \multicolumn{8}{|l|}{ Frequency of group participation } \\
\hline 1 group & 792 & 29.3 & 410 & 29.3 & 382 & 29.4 & \\
\hline 2 groups & 921 & 33.7 & 490 & 33.4 & 431 & 34.1 & \\
\hline 3 groups & 853 & 30.7 & 468 & 30.4 & 385 & 31.3 & \\
\hline$\geq 4$ groups & 186 & 6.2 & 111 & 7.1 & 75 & 5.3 & \\
\hline \multicolumn{8}{|l|}{ Stressors in past 12 months } \\
\hline Parent & 851 & 34.6 & 534 & 40.3 & 317 & 28.0 & $<0.001$ \\
\hline Single parent & 254 & 8.4 & 201 & 12.4 & 49 & 3.8 & $<0.001$ \\
\hline Family stress 12 months before & & & & & & & \\
\hline $\begin{array}{l}\text { the } 9 / 11 \text { attacks } \\
\text { Work stress } 12 \text { months before }\end{array}$ & 865 & 31.2 & 483 & 33.1 & 382 & 28.8 & 0.08 \\
\hline the $9 / 11$ attacks & 238 & 6.8 & 110 & 6.1 & 128 & 7.7 & 0.20 \\
\hline Total no. of recent stressors & & & & & & & 0.16 \\
\hline 0 & 1607 & 59.4 & 846 & 57.3 & 761 & 61.9 & \\
\hline 1 & 717 & 26.9 & 389 & 27.7 & 328 & 25.9 & \\
\hline$\geq 2$ & 428 & 13.7 & 244 & 15.0 & 185 & 12.2 & \\
\hline \multicolumn{8}{|l|}{ Event-related trauma } \\
\hline Peri-event panic & 298 & 13.7 & 274 & 17.6 & 124 & 9.1 & $<0.001$ \\
\hline Directly affected & 808 & 28.3 & 428 & 28.4 & 380 & 28.2 & 0.90 \\
\hline
\end{tabular}

*Unweighted n's represent the actual numbers of persons surveyed. Percentages reflect weighted proportions and may not equal 100 due to rounding.

† Two-tailed $\chi^{2}$ test of significance.

Race/ethnicity, preexisting mental health problems, and marital status explained 10\%, 11\%, and $13 \%$, respectively, of the relation between women's risk of probable lifetime PTSD and each of these variables, and symptoms consistent with peri-event panic in the immediate aftermath of the $9 / 11$ attacks explained $36 \%$ of women's probable lifetime risk of PTSD relative to men.

\section{Re-experiencing and Hyperarousal Symptoms}

The following explanatory variables were significantly associated with criterion B (reexperiencing) symptoms in unstratified analyses: gender $(P<0.001)$, income $(P=0.014)$, age $(P<0.001)$, race/ethnicity $(P=0.04)$, nonsexual assault $(P=0.05)$, sexual assault $(P=0.02)$, preexisting mental health problems $(P<0.001)$, participation in group activities $(P=0.05)$, singleparent status $(P=0.04)$, family stress $(P<0.001)$, work stress $(P=0.013)$, being directly affected by the $9 / 11$ attacks $(P<0.001)$, and peri-event panic $(P<0.001)$. Two of these variables contributed to the gender disparity in re-experiencing: nonsexual assault increased men's risk for PTSD (18\%), although peri-event panic increased women's risk for PTSD more (36\%) (Table IV). Even when these factors were taken into account, women were still at an increased risk for re-experiencing symptoms.

Similar to probable lifetime PTSD and criterion B symptoms, most of the explanatory variables measured in this study were significantly associated with criterion D symptoms: gender $(P<0.001)$, income $(P=0.03)$, age $(P=0.01)$, race/ethnicity $(P<0.001)$, nonassaultive trauma $(P=0.008)$, nonsexual assault $(P<0.001)$, sexu- 


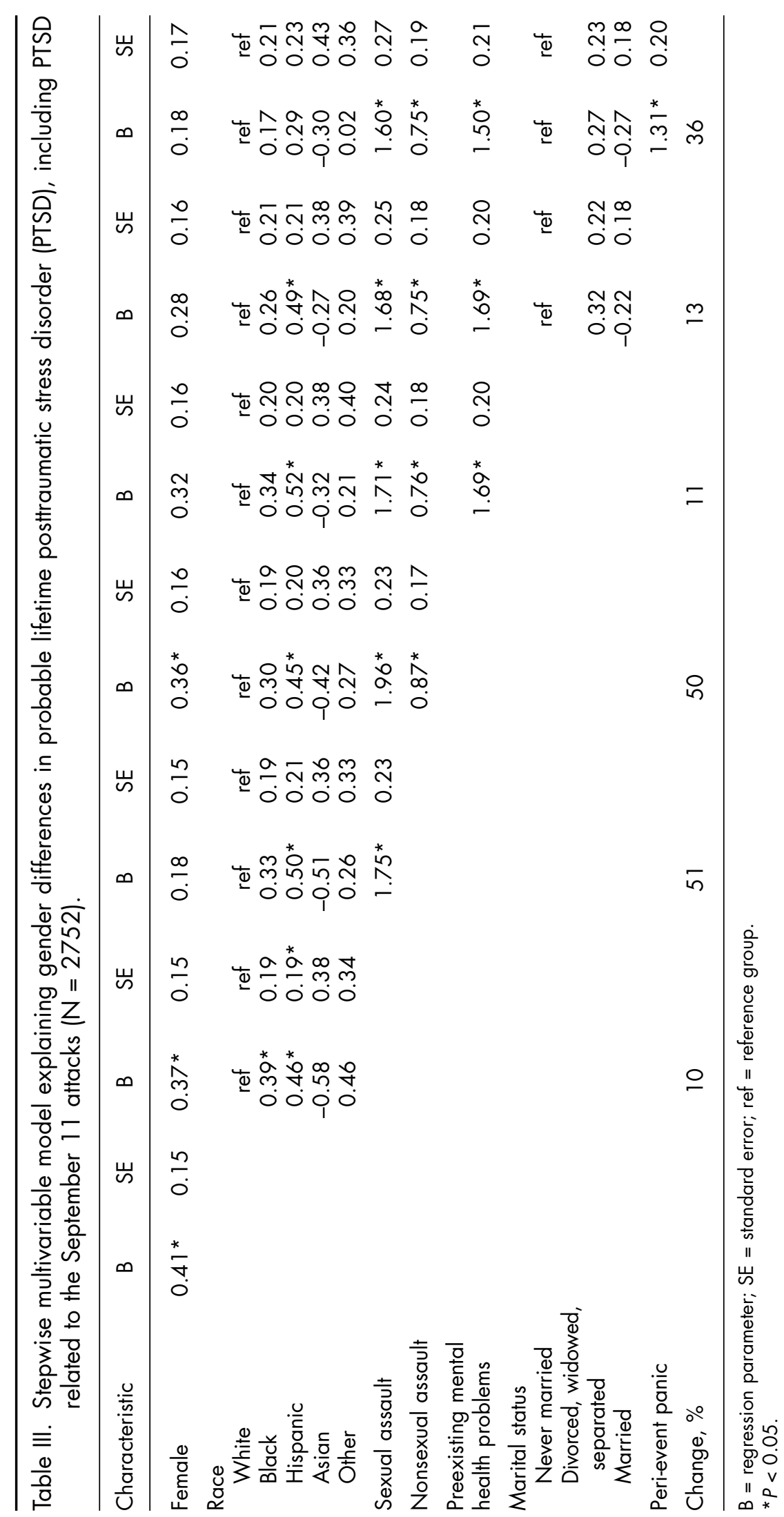


Table IV. Stepwise multivariable model explaining gender differences observed in re-experiencing symptoms related to the September 11 attacks ( $N=2752)$.

\begin{tabular}{|c|c|c|c|c|c|c|c|c|c|c|}
\hline Characteristic & B & SE & B & SE & B & SE & B & SE & B & SE \\
\hline $\begin{array}{l}\text { Female } \\
\text { Nonsexual assault } \\
\text { Peri-event panic } \\
\text { Change, \% }\end{array}$ & 0.41 * & 0.13 & $\begin{array}{l}0.50^{*} \\
0.43^{*}\end{array}$ & $\begin{array}{l}0.13 \\
0.14\end{array}$ & $\begin{array}{c}0.32 * \\
0.40^{*} \\
1.79 * \\
36\end{array}$ & $\begin{array}{l}0.14 \\
0.16 \\
0.16\end{array}$ & $\begin{array}{l}0.39 * \\
0.50 * \\
1.79 * \\
18\end{array}$ & $\begin{array}{l}0.16 \\
0.20 \\
0.16\end{array}$ & $\begin{array}{l}0.49^{*} \\
0.40^{*} \\
2.33^{*} \\
35\end{array}$ & $\begin{array}{l}0.16 \\
0.16 \\
0.28\end{array}$ \\
\hline
\end{tabular}

$\mathrm{B}=$ regression parameter; $\mathrm{SE}=$ standard error.

${ }^{*} P<0.05$.

al assault $(P<0.001)$, preexisting mental health problems $(P<0.001)$, marital status $(P<0.001)$, perceived social support $(P<0.001)$, single-parent status $(P=0.003)$, family stress $(P<0.001)$, work stress $(P<0.001)$, being directly affected by the $9 / 11$ attacks $(P<0.001)$, and peri-event panic $(P<$ $0.001)$. Three of these variables were determined in multivariable analyses to significantly explain gender-related differences in hyperarousal. Sexual assault increased women's risk for PTSD by $25 \%$. Nonsexual assault accounted for higher levels of PTSD in men (31\%), although having had peri-event panic after the 9/11 attacks more than eliminated this effect and increased women's risk for PTSD by $26 \%$ (Table V).

\section{DISCUSSION}

We found that women were more likely than men to report symptoms consistent with a diagnosis of probable lifetime PTSD, and previous experiences of sexual assault, peri-event panic, preexisting mental health problems, race/ ethnicity, and marital status explained the higher prevalence of lifetime PTSD among women.
In contrast, although women did not have higher rates of probable PTSD related to the 9/11 attacks, they were more likely to report reexperiencing and hyperarousal symptoms after September 11. Both previous experiences of sexual assault and probable peri-event panic after the 9/11 attacks explained women's higher rates of hyperarousal symptoms, whereas only the latter explained their higher rate of re-experiencing symptoms.

Consistent with other research, the women in this study were more likely than the men to report symptoms consistent with a diagnosis of probable lifetime PTSD. However, the increased risk of probable lifetime PTSD in women was less pronounced than has been found in other studies. Most population-based studies found that women have up to twice the lifetime risk of PTSD compared with men, whereas in our study women were $\sim 1.4$ times more likely to have lifetime PTSD than were men. ${ }^{1,32}$ This may be due to the higher number of traumatic events reported by the men in this study relative to other population-based studies. For example,

Table V. Stepwise multivariable model explaining gender differences observed in hyperarousal symptoms related to the September 11 attacks $(N=2752)$.

\begin{tabular}{|c|c|c|c|c|c|c|c|c|c|c|c|c|c|c|}
\hline Characteristic & B & SE & B & SE & B & SE & B & SE & B & SE & B & SE & B & SE \\
\hline Female & $0.53^{*}$ & 0.13 & $0.40^{*}$ & 0.13 & $0.58^{*}$ & 0.14 & $0.43^{*}$ & 0.14 & $0.42^{*}$ & 0.15 & $0.44^{*}$ & 0.17 & $0.60 *$ & 0.16 \\
\hline Sexual assault & & & $1.37 *$ & 0.21 & $1.56^{*}$ & 0.22 & $1.46^{*}$ & 0.24 & $1.29^{*}$ & 0.50 & $1.46^{*}$ & 0.24 & $1.46^{*}$ & 0.23 \\
\hline Nonsexual assault & & & & & $0.87^{*}$ & 0.16 & $0.85^{*}$ & 0.16 & $0.84 *$ & 0.16 & $0.86^{*}$ & 0.21 & $0.86 *$ & 0.16 \\
\hline Peri-event panic & & & & & & & $1.72 *$ & 0.17 & $1.72 *$ & 0.17 & $1.72 *$ & 0.17 & $2.27^{*}$ & 0.28 \\
\hline Change, $\%$ & & & 25 & & 31 & & 26 & & & & & & 28 & \\
\hline
\end{tabular}

$\mathrm{B}=$ regression parameter $\mathrm{SE}=$ standard error .

${ }^{*} P<0.05$. 
$10.2 \%$ of men reported experiencing $\geq 4$ traumatic life events in the National Comorbidity Survey (NCS). ${ }^{1}$ By contrast, in our study $21.2 \%$ of the men reported experiencing $\geq 4$ traumatic life events. The women in our sample experienced less cumulative trauma compared with the men, but again, the rates of cumulative trauma were higher in our sample of women when compared with the NCS (10.9\% vs $6.4 \%) .{ }^{1}$ Rates of trauma may be higher in urban populations relative to suburban and rural populations because of greater exposure to previous trauma, particularly violence. ${ }^{9}$ Future PTSD research should examine geographic variability in rates of PTSD, exploring the extent to which residents in communities characterized by high levels of violence are at greater risk for PTSD.

We found that gender differences in PTSD after a disaster were also less pronounced than in studies that examined lifetime rates of PTSD. ${ }^{4}$ One explanation for why the gender gap in PTSD may be less pronounced after disasters is that women may be more vulnerable than men to personal assault, but with respect to other categories of traumatic events, gender differences may be smaller. ${ }^{7,33}$ Our results suggest that both men and women are vulnerable to PTSD following assault. Men's experiences of nonsexual assault increased their probable lifetime risk for PTSD as well as their risk for re-experiencing and hyperarousal symptoms related to the 9/11 attacks relative to women. Women's experiences of rape increased their risk for probable PTSD relative to men.

It is interesting to note that women reported higher rates of re-experiencing and hyperarousal symptoms related to the $9 / 11$ attacks than did men, but reported comparable rates of avoidance/ numbing symptoms. This contrasts with the findings of another study in which women were more likely than men to experience avoidance/ numbing symptoms but not re-experiencing and hyperarousal symptoms. ${ }^{34,35}$ Research is needed to further explore whether women's heightened vulnerability to PTSD is determined by susceptibility to specific symptoms.

Consistent with the literature, we found that preexisting mental health problems were pre- dictors of lifetime PTSD in women. ${ }^{13}$ It is generally believed that preexisting major depressive disorder increases the risk of developing PTSD after exposure to a traumatic event by $>2$-fold. ${ }^{13,36}$ After adjusting for trauma type, the contribution of preexisting mental health problems to explaining gender disparities in probable lifetime PTSD in this study was relatively small. This was also true for race/ethnicity and marital status, 2 additional factors we identified as decreasing women's conditional risk for probable lifetime PTSD, although previous sexual assault was a much stronger predictor of probable lifetime PTSD in women.

Probable peri-event panic was the most important determinant of gender differences in $9 / 11$ criteria B and D symptoms. We found that women were almost twice as likely as men to have had peri-event panic within hours of the $9 / 11$ attacks and that this explained $36 \%$ of the relationship between gender and the reexperiencing symptom group and $26 \%$ of the relationship between gender and the hyperarousal symptom group. Recent research has highlighted the role of peri-event emotional reactions in the subsequent development of PTSD, although relatively little research has examined peri-event panic specifically. ${ }^{37,38}$

It is uncertain whether differential exposure or susceptibility to peritraumatic reactions in the immediate aftermath of a traumatic event contributes to gender-related differences in PTSD. Risk of peritraumatic panic among women may be associated with cognitively-based sensitivity to the social, psychological, and physical consequences of panic or to biologically driven sex differences in panic susceptibility. ${ }^{39,40}$ This is an important area for future research. The identification of peri-event symptomatology may be an avenue for rapid postdisaster interventions that may decrease the eventual burden of PTSD among women. Additional studies are needed to examine the aspects of peri-event emotional reactions that increase risk (eg, dissociation, emotional response, physiological arousal) and how these reactions lead to women's increased risk of PTSD.

In addition to peri-event panic, we examined other factors that may contribute to gender dis- 
parities in PTSD not typically considered in the literature. Contrary to our expectations, we found that women and men reported similar levels of perceived support and group participation as well as similar amounts of recent stress, even when assessed by the type of stress. It is possible that if we had examined negative social support received from social networks instead of positive support, we may have been more successful in uncovering an additional determinant of gender disparities in PTSD. A recent study found a stronger impact of negative rather than positive social support in women compared with men among victims of violent crime, which may help to explain women's higher PTSD risk in civilian samples. ${ }^{41}$

\section{Study Limitations}

This study must be viewed in the context of its limitations. First, we were unable to explain fully the gender disparities in criteria B and D symptoms related to the $9 / 11$ attacks, which suggests that there may be other factors we did not measure that may account for this variance. For example, women may be more likely than men to report symptoms of PTSD because of a systematic bias in gender-related mental health research. ${ }^{42}$ Second, we noted that our modeling technique limited some of the conclusions we could draw in this study. To present the clearest picture of the range of factors that may be important in explaining gender disparities in probable PTSD in a general population sample, we reduced the number of variables in the model by including variables that were associated both with gender and with each of the outcomes in bivariate analysis and that significantly increased (or decreased) women's risk of PTSD. However, some of these variables may have had a high likelihood of co-occurrence (eg, sexual assault and chronic stress) and, as a result, were not significantly related to PTSD in the final model. Third, our measure of preexisting mental health problems was limited in that we did not assess specific diagnoses and their time of onset. Thus we may have underestimated the impact of this factor on women's increased risk of PTSD. Fourth, there were some limitations to our PTSD measures. It is possible that some of the reported cases of PTSD related to the 9/11 attacks were in fact preexisting cases of PTSD due to the absence of a pre-9/11 assessment. Also, the assessments of both probable lifetime PTSD and probable PTSD related to the 9/11 attacks were based on symptoms and did not include distress/functional impairment criteria. Thus, it is possible that probable PTSD was overestimated. The criteria and internal validity of PTSD assessed in this study, as shown here and in other papers using this data set, 30,31 are both reassuring in this regard. Fifth, because our data were based on self-report using telephone interviews, we could not eliminate the possibility that some of our explanatory variables were subject to overreporting bias (eg, reports of previous traumatic experiences and traumatic experiences related to the $9 / 11$ attacks).

Finally, generalizing the findings of this study to the general population and to the context of other disasters must be done with caution because the greater New York metropolitan area may differ from the US population in important ways. For example, residents of the greater New York metropolitan area report higher levels of assault and a greater number of traumatic experiences. In addition, the suggestion in this work of a population-level exposure to a mass traumatic event through indirect mechanisms may not be applicable to disasters in less densely populated areas or in the context of other, less consequential urban disasters. ${ }^{43}$

\section{CONCLUSIONS}

We found that women had a higher lifetime risk of PTSD, but in the 6 months after the 9/11 attacks, women were not more likely than men to have PTSD related to the attacks, although they had higher rates of re-experiencing and hyperarousal symptoms. This gender disparity was largely but not fully explained by women's greater exposure to peri-event panic in the immediate aftermath of the 9/11 attacks. Postdisaster interventions in the general population aimed at alleviating peri-event emotional reactions after mass trauma may decrease PTSD symptoms after such events. 


\section{ACKNOWLEDGMENTS}

This study was supported by grants from the National Institute of Mental Health (RO1 MH 66081-01; Bethesda, Maryland), The United Way of New York City, and the New York Community Trust (New York, New York). Much of the work on this project was completed while Dr. Stuber was a Robert Wood Johnson Health and Society Scholar (Columbia University, New York, New York).

\section{REFERENCES}

1. Kessler RC, Sonnega A, Bromet E, et al. Posttraumatic stress disorder in the National Comorbidity Survey. Arch Gen Psychiatry. 1995;52:10481060.

2. Breslau N, Davis GC, Andreski P, Peterson E. Traumatic events and posttraumatic stress disorder in an urban population of young adults. Arch Gen Psychiatry. 1991;48:216-222.

3. Breslau N, Kessler RC, Chilcoat HD, et al. Trauma and posttraumatic stress disorder in the community: The 1996 Detroit Area Survey of Trauma. Arch Gen Psychiatry. 1998;55:626-632.

4. Norris FH, Foster JD, Weisshaar DL. The epidemiology of sex differences in PTSD across developmental, societal, and research contexts. In: Kimerling R, Ouimette P, Wolfe J, eds. Gender and PTSD. New York, NY: Guilford Press; 2002:207231.

5. North CS, Nixon SJ, Shariat S, et al. Psychiatric disorders among survivors of the Oklahoma City bombing. JAMA. 1999;282:755-762.

6. Pulcino T, Galea S, Ahern J, et al. Posttraumatic stress in women after the September 11 terrorist attacks in New York City. I Womens Health (Larchmt). 2003;12:809-820.

7. Breslau N. Epidemiologic studies of trauma, posttraumatic stress disorder, and other psychiatric disorders. Can J Psychiatry. 2002;47:923-929.

8. Breslau N. Gender differences in trauma and posttraumatic stress disorder. J Gend Specif Med. 2002;5:34-40.

9. Norris FH. Disasters in urban context. J Urban Health. 2002;79:308-314.

10. North CS, Smith EM, Spitznagel EL. Posttraumatic stress disorder in survivors of a mass shooting. Am J Psychiatry. 1994;151:82-88.
11. Kessler RC. Sex differences in the DSM-III-R psychiatric disorders in the United States: Results from the National Comorbidity Survey. J Am Med Womens Assoc. 1998;53:148-158.

12. Orsillo SM, Raja S, Hammond C. Gender issues in PTSD with comorbid mental health disorders. In: Kimerling R, Ouimette P, Wolfe J, eds. Gender and PTSD. New York, NY: Guilford Press; 2002:207-231.

13. Breslau N, Davis GC, Andreski P, et al. Sex differences in posttraumatic stress disorder. Arch Gen Psychiatry. 1997;54:1044-1048.

14. Nixon RD, Bryant RA. Peritraumatic and persistent panic attacks in acute stress disorder. Behav Res Ther. 2003;41:1237-1242.

15. Falsetti SA, Resnick HS, Dansky BS, et al. The relationship of stress to panic disorder: Cause or effect? In: Mazure CM, ed. Does Stress Cause Psychiatric Illness? Washington, DC: American Psychiatric Press; 1995:111-147.

16. Brewin CR, Andrews B, Valentine JD. Meta-analysis for risk factors for posttraumatic stress disorder in trauma-exposed adults. I Consult Clin Psychol. 2000;68:748-766.

17. Pierce T, Baldwin MW, Lydon JE. A relational schemas approach to social support. In: Pierce GR, Lakey B, Sarason IG, Sarason BR, eds. Sourcebook of Social Support and Personality. New York, NY: Plenum Press; 1997:19-47.

18. Lazarus RS, Folkman S. Stress, Appraisal, and Coping. New York, NY: Springer Publication Co; 1984.

19. Weissman MM, Neria Y, Das A, et al. Gender differences in posttraumatic stress disorder among primary care patients after the World Trade Center attack of September 11, 2001. Gend Med. 2005;2:76-87.

20. Solomon SD. Gender differences in response to disaster. In: Weidner G, Kopp MS, Kristenson M, eds. Heart Disease: Environment, Stress and Gender. Amsterdam, the Netherlands: IOS Press; 2002:327.

21. Turner RJ, Marino F. Social support and social structure: A descriptive epidemiology. J Health Soc Behav. 1994;35:193-212.

22. Norris FH, Perilla JL, Riad JK, et al. Stability and change in stress, resources, and psychological distress following natural disaster: Findings from Hurricane Andrew. Anxiety, Stress and Coping. 1999;12:363-396.

23. Aube J, Fleury J, Smetana J. Changes in women's roles: Impact on and social policy implications 
for the mental health of women and children. Dev Psychopathol. 2000;12:633-656.

24. Kilpatrick DG, Resnick HS, Freedy JR, et al. Posttraumatic stress disorder field trial: Evaluation of the PTSD construct-criteria A through E. In: Widiger TA, Frances AJ, Pincus MB, et al, eds. DSM-IV Sourcebook, Volume 4. Washington, DC: American Psychiatric Association Press; 1998: 803-844.

25. Stamm BH. Contextualizing death and trauma: A preliminary endeavor. In: Figley CR, ed. Death and Trauma. New York, NY: Brunner/Mazel; 1996:3-21.

26. Sherbourne CD, Stewart AL. The MOS social support survey. Soc Sci Med. 1991;32:705-714.

27. Centers for Disease Control. Diagnostic interview schedule (DIS). In: Health Status of Vietnam Veterans (Supplement C: Medial and psychological procedure manuals and forms). Atlanta, Ga: US Dept of Health and Human Services; 1989:405-499.

28. American Psychiatric Association. Diagnostic and Statistical Manual of Mental Disorders, Fourth Edition. Washington, DC: American Psychiatric Association; 1995.

29. The American Association for Public Opinion Research. 2003. Final dispositions of case codes and outcome rates for surveys. Available at: http:// www.aapor.org/pdfs/newstandarddefinitions.pdf. Accessed February 11, 2005.

30. Galea S, Vlahov D, Resnick H, et al. Trends in probable post-traumatic stress disorder in New York City after the September 11 terrorist attacks. Am J Epidemiol. 2003;158:514-524.

31. Galea S, Vlahov D, Tracy M, et al. Hispanic ethnicity and post-traumatic stress disorder after a disaster: Evidence from a general population survey after September 11. Ann Epidemiol. 2004;14: 520-531.

32. Norris FH. Epidemiology of trauma: Frequency and impact of different potentially traumatic events on different demographic groups. J Consult Clin Psychol. 1992;60:409-418.
33. Stein MB, Walker JR, Forde DR. Gender differences in susceptibility to posttraumatic stress disorder. Behav Res Ther. 2000;38:619-628.

34. Breslau N, Chilcoat HD, Kessler RC, et al. Vulnerability to assaultive violence: Further specification of the sex difference in post-traumatic stress disorder. Psychol Med. 1999;29:813-821.

35. Solomon SD, Canino GJ. Appropriateness of $D S M-I I I-R$ criteria for posttraumatic stress disorder. Compr Psychiatry. 1990;31:227-237.

36. Shalev AY, Freedman S, Peri T, et al. Prospective study of posttraumatic stress disorder and depression following trauma. Am J Psychiatry. 1998;155: 630-637.

37. Resnick HS, Kilpatrick DG, Dansky BS, et al. Prevalence of civilian trauma and posttraumatic stress disorder in a representative national sample of women. J Consult Clin Psychol. 1993;61:984-991.

38. Harvey AG, Bryant RA. The relationship between acute stress disorder and posttraumatic stress disorder: A 2-year prospective evaluation. J Consult Clin Psychol. 1999;67:985-988.

39. Reiss S, McNally RJ. Expectancy model of fear. In: Reiss S, Bootzin RR, eds. Theoretical Issues in Behavior Therapy. New York, NY: Academic Press; 1985: 107-121.

40. Stewart SH, Taylor S, Baker JM. Gender differences in dimensions of anxiety sensitivity. I Anxiety Disord. 1997;11:179-200.

41. Fullerton CS, Ursano RJ, Epstein RS, et al. Gender differences in posttraumatic stress disorder after motor vehicle accidents. Am J Psychiatry. 2001;158: 1486-1491.

42. Saxe G, Wolfe J. Gender and posttraumatic stress disorder. In: Saigh PA, Bremner JD, eds. Posttraumatic Stress Disorder: A Comprehensive Text. Boston, Mass: Allyn \& Bacon; 1999:160-179.

43. Galea S, Resnick H. Posttraumatic stress disorder in the general population after mass terrorist incidents: Considerations about the nature of exposure. CNS Spectr. 2005;10:107-115.

Address correspondence to: Sandro Galea, MD, MPH, DrPH, Associate Professor, Department of Epidemiology, University of Michigan School of Public Health, 1214 South University, Room 243, Ann Arbor, MI 48104-2548. E-mail: sgalea@umich.edu 